\title{
Cournot and Bertrand Competition in the Software Industry
}

\author{
Luciano Fanti ${ }^{1}$ and Domenico Buccella ${ }^{2}$ \\ ${ }^{1}$ Department of Economics and Management, University of Pisa, Via Cosimo Ridolfi 10, 56124 Pisa, Italy \\ ${ }^{2}$ Department of Economics, Kozminski University, Jagiellońska Street 57/59, 03-301 Warsaw, Poland \\ Correspondence should be addressed to Domenico Buccella; buccella@kozminski.edu.pl
}

Received 13 July 2016; Revised 31 October 2016; Accepted 4 December 2016; Published 27 February 2017

Academic Editor: Jean Paul Chavas

Copyright (c) 2017 Luciano Fanti and Domenico Buccella. This is an open access article distributed under the Creative Commons Attribution License, which permits unrestricted use, distribution, and reproduction in any medium, provided the original work is properly cited.

\begin{abstract}
In a software industry based on a platform firm and two firms producing differentiated applications complementary to the platform, we investigate the effects on profits and welfare of the choice of different contracts (price versus quantity) by the application firms. In contrast to the traditional result, (1) equilibrium profits are higher under Cournot or Bertrand competition depending upon the degree of complementarity between platform and application producers as well as the degree of substitutability between applications; (2) the social welfare may be higher under Cournot when the application products are highly substitutable.
\end{abstract}

\section{Introduction}

This paper is mainly related to two recent industrial organisation literature themes: (1) the profitability and efficiency properties of the duality of prices and quantities in differentiated duopoly, early analysed by Singh and Vives [1], and (2) the economics of networks and two-sided markets (e.g., [2-5]).

As Singh and Vives show $(1984)^{1}$ (and later [6-8]), the comparison in terms of profitability and welfare between the outcomes of quantity and price competition leads to clearcut results: (1) firms' profits in a duopoly context are higher when firms compete in quantities ( $\dot{a}$ la Cournot) than when competing in prices (à la Bertrand) if products are (imperfect) substitutes (and, vice versa, when goods are complements); (2) social welfare is always larger under Bertrand independent of whether products are substitutes or complements.

In this paper, we deal with a network industry and analyse a setting of a platform firm (selling, for example, operating systems) with two complementary applications produced by two independent firms (selling, for example, application software). In this setting, the sales of each good depend on its own price as well as on the sales of the complementary goods (that is, there are "network effects"). ${ }^{2}$ We consider the case in which the independent applications providers may compete on either quantity or price and their applications may be either substitutes or complements between them. Therefore we assume that (1) applications are complements to the network and (2) different applications can be substitutes or complements. In particular, the present paper tackles the issue of the Cournot-Bertrand profit and welfare differentials in this network industry.

The previous literature has dealt with this classical issue in other different contexts. Only to mention the more recent works, Zanchettin [9] carried out this analysis in the context of firms' asymmetric costs and demands, Chirco and Scrimitore [10] and Pal [11] in a framework with managerial delegation, Alipranti et al. [12] in a vertically related market, Mukherjee et al. [13] and Nguyen et al. [14] in the presence of different production technologies and technology licensing, respectively, Fanti and Meccheri [15] and Choi [16] in the presence of labour unions, and Fanti and Meccheri [17] in a framework with both unions and managerial delegation. Hinloopen and Vandekerckhove $[18,19]$ considered the efficiency of Cournot and Bertrand equilibria in a duopoly where firms invest in process R\&D that generates input spillovers; C. H. Tremblay and V. J. Tremblay [20] investigated the outcomes of the mixed Cournot-Bertrand model when the degree of product differentiation is allowed to vary, but the choice of the strategic variable is not allowed, while Tremblay et al. [21] showed that when firms are given the choice of competing in output or in price, cost asymmetries can lead to a Nash 
equilibrium where one firm competes in output and the other competes in price.

In the current paper, we analyse the industry implications in terms of prices, output, profitability, and social welfare of the two Cournot and Bertrand modes of competition. Therefore, our paper contributes to the above-mentioned literature by analysing a framework which has not been explored before.

In particular, we address the issue of whether the standard results on the ranking of Cournot and Bertrand equilibrium outcomes under differentiated duopoly are robust to the inclusion of a two-sided market in a software industry. ${ }^{3}$

The structure of our model is similar to that of Economides and Katsamakas [22]; however, those authors abstract from the issue of the ranking of Cournot and Bertrand equilibrium outcomes. In particular, we consider both Cournot and Bertrand solutions to the noncooperative product market game.

More specifically, in our model, a firm that controls a proprietary platform makes strategic pricing decisions for the products it sells directly to the end-user ${ }^{4}$ and two independent firms compete between them in the application market. There are, on one hand, complementarities between the platform and each application, and, on the other hand, users have a preference for application variety. Thus, a network effect arises: an increase of the size and sales of the applications network increase the demand of the platform.

Since more than one application is compatible to the same platform, then we determine how the interaction between the applications in terms of complementarity or substitutability affects the equilibrium under Bertrand and Cournot competition in the application market, and we compare the profitability and social welfare of the two modes of competition.

The key results of the paper are as follows. We find that the Bertrand competition can be more profitable than the Cournot one when users have a distinct preference for application variety. By contrast, the social welfare can be larger under Cournot than under Bertrand when users consider applications very substitutable between them (and not too much complementary with the platform). Moreover, the platform firm prefers that application providers compete on price; however, when both the maximum sales of the platform are large in comparison with those of the applications and the latter are complements between them and are strongly complementary with the platform, the platform firm prefers that application providers compete on quantities.

The policy implication of our results is as follows. To design appropriate public competition policies, it is important to carry out an analysis of the whole prices/quantities system because if only a part of the system is considered, significant features of the strategic interaction in the industry can be neglected or may remain unexplained. The empirical implication of our results is that price (resp., quantity) competition should be observed more often when application providers offer poorly (resp., highly) substitutable applications.

The remainder of the paper is organised as follows. Section 2 presents the basic ingredients of our model. Section 3 deals with the profitability and welfare analysis of the two modes of competition. Section 4 drives the paper to its conclusion with some final considerations and outlining the future directions of research.

\section{The Model}

This section develops the model of the paper analysing a setting of a platform with two complementary applications. The platform firm sells platform (for example, operating system) $A$, while the independent firms, denoted as 1 and 2, sell varieties 1 and 2 of good $B$, which is complementary to the platform (for example, application software) but can be either substitutes or complements to each other.

The platform firm, which is indicated by the subscript $A$, sells the platform to end-users at price $p_{A}$, while the two independent applications are sold at prices $p_{1}$ and $p_{2}$, respectively.

The linear direct demand functions of platform $A$ and applications $B_{i}$, are, respectively

$$
\begin{aligned}
& q_{A}\left(p_{A}, p_{1}, p_{2}\right)=a_{A}-p_{A}-d\left(p_{1}+p_{2}\right), \\
& q_{1}\left(p_{A}, p_{1}, p_{2}\right)=a_{1}-d p_{A}-p_{1}+c p_{2} \\
& q_{2}\left(p_{A}, p_{1}, p_{2}\right)=a_{2}-d p_{A}-p_{2}+c p_{1} .
\end{aligned}
$$

The quantity intercept $a_{A}$ of the platform demand (representing actual sales when all prices are zero) depends on the inherent quality and functions of the platform and the variety of applications that are compatible to the platform. The parameter $d$ measures the strength of the complementarity between the platform and the application. ${ }^{5}$ Parameter $c$ measures the degree of substitution between applications 1 and 2. We assume symmetric applications' demands; that is, $a_{1}=a_{2}=a, 1>2 d, 1>c$, and $1>d+c$. The maximum sales of the platform, $a_{A}$, can be larger than the maximum sales of the application; that is, $a \leq a_{A}{ }^{6}$ The inverse demand functions are given by

$$
\begin{aligned}
& p_{A}\left(q_{A}, q_{1}, q_{2}\right)=\frac{q_{A}(1-c)-d q_{1}-a_{A}(1-c)+d\left(2 a-q_{2}\right)}{2 d^{2}+c-1}, \\
& p_{1}\left(q_{A}, q_{1}, q_{2}\right) \\
& =\frac{-d q_{A}(1+c)+\left(1-d^{2}\right) q_{2}+\left(a_{A} d-a\right)(1+c)+q_{1}\left(c+d^{2}\right)}{(1+c)\left(2 d^{2}+c-1\right)} \\
& p_{2}\left(q_{A}, q_{1}, q_{2}\right) \\
& =\frac{-d q_{A}(1+c)+\left(1-d^{2}\right) q_{1}+\left(a_{A} d-a\right)(1+c)+q_{2}\left(c+d^{2}\right)}{(1+c)\left(2 d^{2}+c-1\right)} .
\end{aligned}
$$

We assume zero costs, as Economides and Katsamakas (2006), because in the software production marginal costs are generally negligible and fixed costs would not be relevant because entry and exit are not discussed. Therefore profit functions for platform and applications are, respectively,

$$
\pi_{A}=p_{A} q_{A},
$$




$$
\begin{aligned}
& \pi_{1}=p_{1} q_{1}, \\
& \pi_{2}=p_{2} q_{2} .
\end{aligned}
$$

Now, we study the equilibrium outcomes of the cases in which application providers compete between them on either price or quantity, that is, the cases in which application providers might choose different strategic variables with respect to that the platform firm chooses. More specifically (i) application firms 1 and 2 behave alternatively either as Bertrand-type firms by competing in price $\left(p_{1}\right.$ and $\left.p_{2}\right)$ or as Cournot-type firms by competing in output $\left(q_{1}\right.$ and $q_{2}$ ); (ii) platform firm $A$ behaves only as a Bertrand-type firm, competing in price $\left(p_{A}\right)$.

Therefore, we compare the outcomes of a "BertrandBertrand" type model in which both platform and application firms compete in price and a "Bertrand-Cournot" type model in which platform firm competes in price and the others compete in output. ${ }^{7}$ Firms are profit maximisers, and information is complete.

We assume that firms set their choice variable simultaneously and noncooperatively, and we characterize the Nash equilibria in the two different cases.

2.1. The Case of "Bertrand-Bertrand" Competition. Platform firm and application providers maximise their profits by choosing price as strategic variable. Standard calculations, according to which firms A, 1 , and 2 simultaneously maximise their profits (see (5), (6), and (7), resp.) by using the direct demand functions (see (1), (2), and (3), resp.), lead to the following equilibrium prices, quantities, and profits:

$$
\begin{aligned}
& p_{A}=\frac{a_{A}(2-c)-2 a d}{2\left(2-c-d^{2}\right)}, \\
& p_{1}=p_{2}=\frac{a_{A} d-2 a}{2\left(2-c-d^{2}\right)}, \\
& q_{A}=\frac{a_{A}(2-c)-2 a d}{2\left(2-c-d^{2}\right)} \\
& q_{1}=q_{2}=\frac{a_{A} d-2 a}{2\left(2-c-d^{2}\right)}, \\
& \pi_{A}=\frac{\left[a_{A}(2-c)-2 a d\right]^{2}}{4\left[2-c-d^{2}\right]^{2}}, \\
& \pi_{1}=\pi_{2}=\frac{\left[a_{A} d-2 a\right]^{2}}{4\left[2-c-d^{2}\right]^{2}} .
\end{aligned}
$$

The conditions for having positive quantities, prices, and profits under "Bertrand-Bertrand" competition are the following:

$$
\begin{aligned}
& p_{A}, q_{A}>0 \Longleftrightarrow \\
& \frac{a_{A}}{a}>\frac{2 d}{(2-c)}
\end{aligned}
$$

$$
\begin{gathered}
p_{1}, q_{1}, p_{2}, q_{2}>0 \Longleftrightarrow \\
\frac{a_{A}}{a}>\frac{2}{d} .
\end{gathered}
$$

2.2. The Case of "Bertrand-Cournot" Competition. The application providers choose the Cournot mode of competition, while the platform firm still considers price as choice variable for maximising its profits. As in the "Bertrand-Bertrand" case, standard techniques allow us to obtain the following equilibrium outcomes (where the superscript $C$ denotes the "Bertrand-Cournot" case) (more details are in Appendix):

$$
\begin{aligned}
& p_{A}{ }^{C}=\frac{a_{A}\left(2-c-c^{2}\right)-2 a d}{2\left[2-c^{2}-c-d^{2}(3+c)\right]}, \\
& p_{1}{ }^{C}=p_{2}{ }^{C}=\frac{a_{A} d(1-c)-2 a\left(1-d^{2}-c\right)}{2(1-c)\left[2-c^{2}-c-d^{2}(3+c)\right]}, \\
& q_{A}{ }^{C}=\frac{\left[a_{A}(1-c)(1+c)-2 a d\right]\left(1-c-2 d^{2}\right)}{\left[2-c^{2}-c-d^{2}(3+c)\right](1-c)}, \\
& q_{1}{ }^{C}=q_{2}{ }^{C}=\frac{a_{A} d(1-c)-2 a\left(1-d^{2}-c\right)(1+c)}{2\left[2-c^{2}-c-d^{2}(3+c)\right]}, \\
& \pi_{A}{ }^{C}=\frac{\left[a_{A}\left(2-c-c^{2}\right)-2 a d\right]^{2}\left(1-2 d^{2}-c\right)}{4(1-c)\left[2-c^{2}-c-d^{2}(3+c)\right]^{2}}, \\
& \pi_{1}{ }^{C}=\pi_{2}{ }^{C} \\
& =\frac{\left[a_{A} d(1-c)-a\left(2+2 d^{2}-2 c\right)\right]^{2}(1+c)}{4(1-c)\left[2-c^{2}-c-d^{2}(3+c)\right]^{2}} .
\end{aligned}
$$

The conditions for having positive quantities, prices, and profits under "Bertrand-Cournot" competition" are the following:

$$
\begin{aligned}
p_{A}{ }^{C}, q_{A}{ }^{C} & >0 \Longleftrightarrow \\
\frac{a_{A}}{a}> & \frac{2 d}{(1-c)(2-c)} ; \\
p_{1}{ }^{C}, q_{1}{ }^{C}, p_{2}{ }^{C}, q_{2}{ }^{C} & >0 \Longleftrightarrow \\
\frac{a_{A}}{a} & >\frac{2\left(1-c-d^{2}\right)}{d(1-c)} .
\end{aligned}
$$

It is easy to see that condition (C.4) is the most stringent one for ensuring the feasibility of the software market regardless of the mode of competition. Condition (C.4) shows that if the degree of complementary between the platform and the applications is sufficiently high, prices and quantities under Cournot are always negative (e.g., when $a_{A} / a=1.1$, the nonnegativity requires that $d<0.54)$. Conversely, a sufficiently low degree of complementary ensures that they are always positive (e.g., when $a_{A} / a=1.1, d<0.23$ ). Finally, for intermediate values of the degree of complementary (e.g., when $\left.a_{A} / a=1.1,0.23<d<0.54\right)$, the higher the degree of 
substitutability between applications is, the more likely prices and quantities under Cournot can become negative.

Armed with the above reported equilibrium outcomes, we are now in a position to investigate in the next section whether the standard results with regard to the ranking of Cournot and Bertrand equilibrium outcomes under differentiated duopoly are robust to the inclusion of a two-sided market in a software industry.

\section{Profitability and Welfare Analysis}

Let us define the following Cournot-Bertrand profit differentials for the platform firm and the applications firms, respectively (the explicit expressions are reported in Appendix):

(1) $\Delta \pi_{A}=\pi_{A}-\pi_{A}^{C}$ (which represents the platform firm's profit differential between the cases in which application firms play either Bertrand or Cournot games).

(2) $\Delta \pi=\pi-\pi^{C}$ (which represents the application firms' profit differential between the cases in which they play either Bertrand or Cournot games).

The traditional welfare results in the standard model of differentiated duopoly with exogenous marginal costs establish that Bertrand competition yields higher welfare at equilibrium. In this section, we investigate whether the conventional wisdom still holds when the interaction between firms in a software industry with network effects may influence welfare.

At equilibrium, the consumer surplus (CS) can be defined as

$$
\mathrm{CS}=\frac{\left(a_{A}-p_{A}\right) q_{A}}{2}+\frac{\left(a-p_{1}\right) q_{1}}{2}+\frac{\left(a-p_{2}\right) q_{2}}{2}
$$

and the social welfare ${ }^{9}$ is defined as

$$
S W=\mathrm{CS}+\pi_{A}+\pi_{1}+\pi_{2}
$$

We define the welfare differential as $\Delta \mathrm{SW}=\mathrm{SW}-\mathrm{SW}^{\mathrm{C}}$ (the explicit expressions are in Appendix). It is easy to see that the nonlinearity of the resulting expressions (in Appendix) for the profits and social welfare differentials prevents us from using algebraic methods to show next Results 1 and 2 (which are, however, exhaustively illustrated trough numerical and graphical analysis and analytically proven in Appendix).

Since all the above differentials are functions of four parameters, we can resort to a two-parameter graphical analysis in the plane $(c, d)$ for fixed representative values of the maximal sales of the different firms, $a_{A}$ and $a$. In other words, we investigate whether and how the preferred mode of competition by application providers varies with the features of their products in terms of substitutability/complementarity, in dependence of how platform users may not buy the applications (i.e., the distance between the demand intercepts). Subsequently, we also investigate the effects of the preferred mode of competition on the welfare of (platform and providers) firms, consumers, and society as a whole.

We show, for illustrative purposes, two cases in which the maximum sales of the platform are similar to (resp., large in comparison with) those of the applications. Note that all the conclusions, summarised in Results 1 and 2, qualitatively hold independent of the difference in the maximum sales. The sole exception regards the preference of the platform firm concerning the choice of the mode of competition by its complementary firms, which may change when the difference in the maximum sales becomes sufficiently large.

Result 1. If the maximal sales of the platform are close to those of the application providers, then the platform firm always prefers that application providers play a Bertrand game in their market. However, if the maximal sales of the platform are sizably larger than those of the application providers, then it may prefer that application providers play a Cournot game, provided that its degree of complementarity with the applicative products is high and the latter are sufficiently complements between them.

Proof. This derives from the fact that the sign of profit differential $\Delta \pi_{A}=\pi_{A}-\pi_{A}^{C}$ is negative for most values of the four parameters, as exhaustive graphical and numerical simulations (not reported here for economy of space) have shown. However, provided that $a_{A}>a_{A}{ }^{\circ}$ (which requires that $a_{A}>a$ ), if platform and applications are strong complements and applicative products are strongly complementary between them, then the sign of profit differential may become negative, as occurs in region $\mathrm{D}$ of Figure 2. The threshold value of $a_{A}{ }^{\circ}(a, c, d)$ (for which the platform's profits differential changes its sign) is formally derived in (A.2) in Appendix.

Result 2. If applications are substitutable goods, then (i) profits under Bertrand competition are higher than those under Cournot, provided that users have a distinct preference for application variety (and the degree of complementarity between applications and platform is sufficiently low); (ii) by contrast, the social welfare ${ }^{10}$ may be larger under Cournot than under Bertrand when users consider applications highly substitutable between them (and not too much complementary with the platform). Moreover both results (i) and (ii) qualitatively hold independent of whether the market "size" of platform and applications are similar or different.

Proof. Result of part (i) is derived by the fact that the sign of profit differential $\Delta \pi=\pi-\pi^{C}$ becomes negative when $a_{A}>a_{A}{ }^{\circ}$, as occurs in regions $\mathrm{B}$ and $\mathrm{C}$ in Figures 1 and 2 and the threshold value of $a_{A}{ }^{\circ}(a, c, d)$ (for which the application providers' profits differential changes its sign) is formally derived in (A.4) in Appendix; result of part (ii) is derived by the fact that the sign of social welfare differential $\Delta S W=$ $\mathrm{SW}-\mathrm{SW}^{\mathrm{C}}$ becomes negative when $a_{A}>a_{A}{ }^{\circ 00}$, as occurs in region $C$ in Figures 1 and 2 and the threshold value of $a_{A}{ }^{000}(a, c, d)$ is formally derived in (B.1) in Appendix.

Figures 1 and 2 exhaustively display the above results. In Figure 1 (resp., Figure 2) it is assumed that the maximum sales of the platform and the applications are similar (resp., sufficiently different). In the shadowed space above the red line $q_{1}=q_{2}<0$ and, thus, the market would be meaningless. 


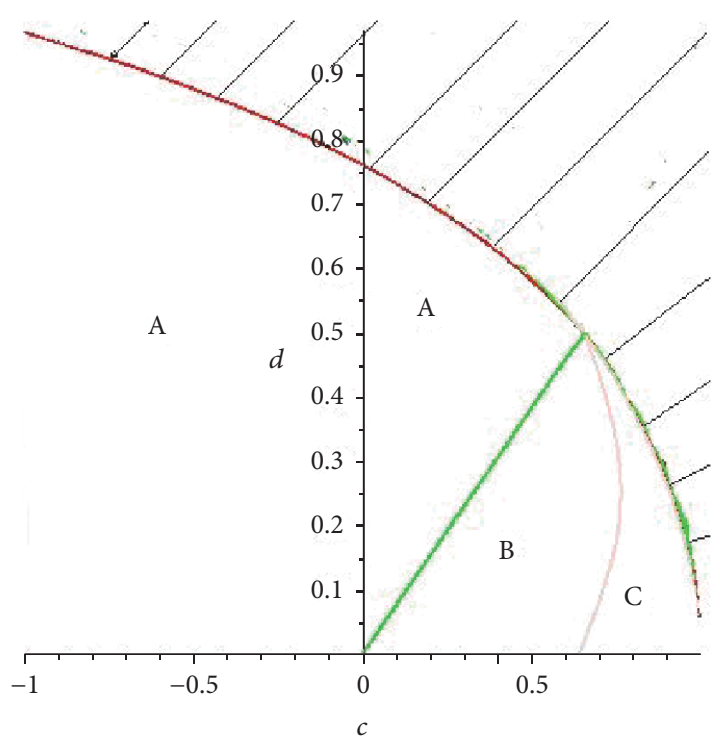

FIgURE 1: Plot of the Cournot-Bertrand profit differential for application firms $(\Delta \pi=0)$, social welfare differential $(\Delta S W=0)$, and $q_{1}=q_{2}=0$ in the parametric plane $(c, d) . \Delta \pi=0$, green line; $\Delta \mathrm{SW}=0$, pink line; and $q_{1}=q_{2}=0$, red line. Parameter set: $a_{A}=1.1 ; a=1$.

To the left (resp., right) of the profit indifference curve $(\Delta \pi=$ 0 ) profits of application firms are larger under Bertrand (resp., Cournot). To the left (resp., right) of the social welfare indifference curve $(\Delta S W=0)$, welfare is larger under Bertrand (resp., Cournot).

In the case of similarity of the demand intercept of the platform and the applications (i.e., Figure 1) $\Delta \pi_{A}<0$ in the entire parametric space. By contrast, in the case of sizable difference of the demand intercept between the platform and the applications (i.e., Figure 2) above (resp., below) the platform firm's profit indifference curve $\left(\Delta \pi_{A}=0\right)$ platform profits are higher when application firms play Cournot (resp., Bertrand).

From Figures 1 and 2, illustrating Results 1 and 2, we observe the following: (i) in region D platform firm prefers that application providers compete over quantity (conversely, over price in the other regions); (ii) in regions $\mathrm{A}$ and $\mathrm{D}$ (resp., $B$ and $C$ ) price (resp., quantity) competition is more profitable than quantity (resp., price) competition for application firms; (iii) in regions $\mathrm{A}, \mathrm{D}$, and $\mathrm{B}$ (resp., C) society prefers that application firms compete between them over price (resp., quantity).

Remark 1. In region A, all agents, platform firm, applications firms, and consumers, prefer Cournot-Cournot competition between application firms.

This means that in such a case the choice of Cournot competition represents the Pareto-superior choice. This Paretosuperior outcome may occur, by interpreting the economic parameters in region $\mathrm{A}$, when applicative products tend to be sufficiently complements between them and/or the degree of complementarity between platform and applications tends

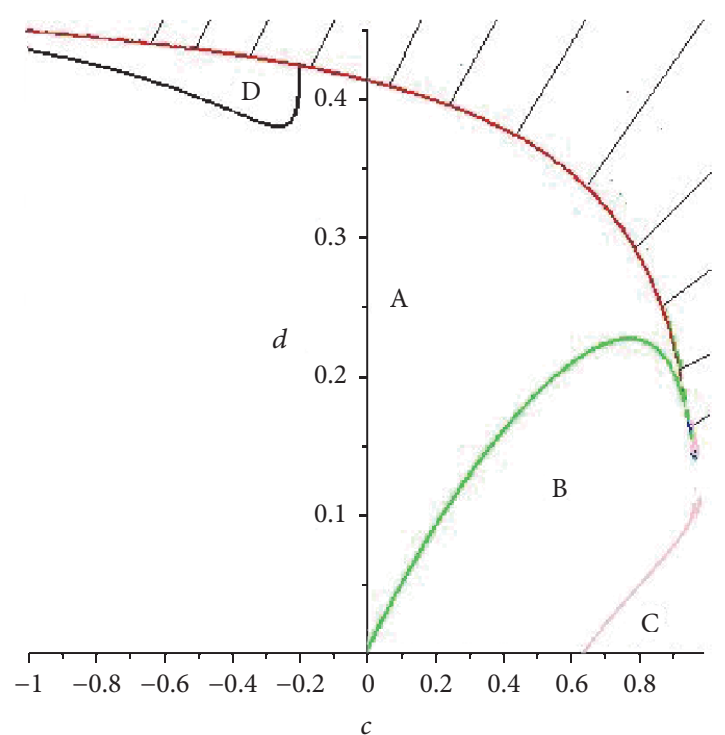

FIgURE 2: Plot of the platform firm's profit differential $\left(\Delta \pi_{A}=0\right)$, Cournot-Bertrand profit differential for application firms $(\Delta \pi=0)$, social welfare differential $(\Delta \mathrm{SW}=0)$, and $q_{1}=q_{2}=0$ in the parametric plane $(c, d) . \Delta \pi_{A}=0$, black line; $\Delta \pi=0$, green line; $\Delta \mathrm{SW}=0$, pink line; and $q_{1}=q_{2}=0$, red line. Parameter set: $a_{A}=4$; $a=1$.

to be large. Conversely, if applicative products tend to be substitutes and be less complement with the platform, then the choice of mode of competition by application providers generates always a conflict of interests with platform firm and/or consumers.

Note that the Pareto-superiority implies that, moving outside region $\mathrm{A}$, at least one agent is harmed (for instance, moving from region $\mathrm{A}$ to region $\mathrm{B}$, where applications firms would choose a Cournot behaviour, consumers, platform firm, and society overall would be worse off), but it does not mean that in region A of Pareto-superiority their single payoffs are maximal.

Indeed, if we investigate the achievable levels of social welfare of the two Bertrand and Cournot cases under different parametric situations, we obtain the following remark.

Remark 2. The maximal social welfare is achieved when application providers compete on quantities and their applicative products are strong substitutes between them. Moreover, social welfare is always monotonically increasing in the applicative products's substitutability.

This remark is clearly illustrated by Figure 3 . Notice that the picture displayed in Figure 3 is qualitatively invariant to any parameter set and thus Remark 2 always holds.

While the welfare-enhancing role of the parameter $c$ is in line with the intuition because a higher degree of substitutability implies greater competition in the applications market, the welfare-superiority of the Cournot competition (for sufficiently large values of $c$ ) is in sharp contrast to the traditional result in a standard oligopolistic industry (i.e., Singh and Vives, 1984, where Bertrand competition is always 


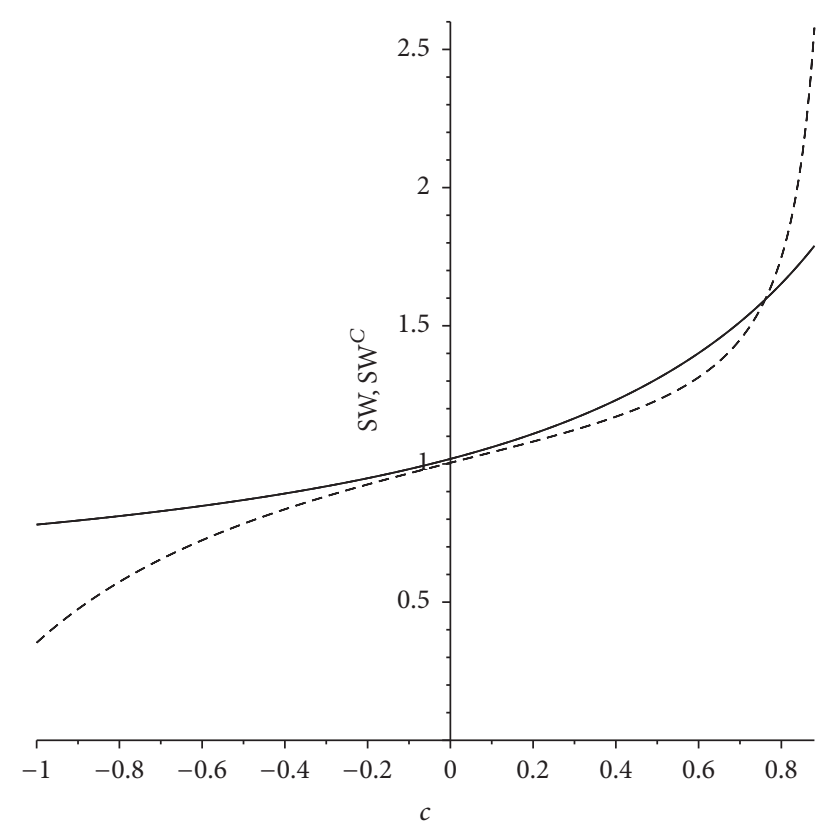

Figure 3: Plot of the social welfare functions when application providers play Bertrand (SW, solid line) and Cournot (SW ${ }^{C}$, dashed line) for a varying applicative products differentiation parameter, $c$ (other parameters: $a_{A}=1.1, a=1$, and $d=0.2$ ).

social welfare-preferred). This finding is due to the peculiarity of the software industry and two-sided markets.

The economic intuition behind Result 2 and Remark 2 is as follows. In the presence of substitutable products in the market for applications, the complementarity relationship with the platform firm (which applies a pricing strategy) implies that also application providers find it more profitable to use the price as strategic variable in the competition between them. Moreover, when applications are highly substitutable between them and, thus, applications providers' profits are higher under Cournot, although the consumer surplus remains higher under Bertrand, the advantage of Cournot competition in terms of applications firms' profits overweighs the disadvantage of the consumers' welfare, and thus social welfare becomes larger under Cournot. Therefore, the current model suggests that if the goal of society is to maximise welfare, then policy officials should encourage application providers to compete in output and discourage excessive product differentiation. ${ }^{11}$

\section{Conclusions}

This paper compares Cournot and Bertrand equilibria in a software industry based on a platform firm and two firms producing differentiated applications that are complementary to the platform, which may compete between them on price or quantity. We show that the standard result that Cournot equilibrium profits exceed those under Bertrand competition, when the differentiated duopoly game is played with imperfect substitutes, may be reversed. In particular, equilibrium profits of application firms are higher under Cournot or Bertrand competition depending upon the degree of complementarity between platform and application producers and the degree of substitutability between applications. We show that the standard result for the market game played by application firms holds only when applications are not too differentiated. As regards the platform firm, profits are generally higher when application providers compete on price. However, the platform firm prefers that application providers compete on quantities when the platform's maximum sales are large with respect to those of application providers, and applications are both complements between them and have strong complementarity with the platform.

Moreover, we compare social welfare under the two modes of competition, showing that also the traditional welfare results in the fact that standard model of differentiated duopoly (establishing that Bertrand competition always yields higher welfare at equilibrium) is reversible when application products are sufficient substitutes.

These results, which are in contrast to the common wisdom by Singh and Vives (1984), reveal that competition issues should be analysed not considering separately the platform market or the applications markets but rather the combined interaction across these markets. ${ }^{12}$

Finally, other future directions of research may be the following. First, while the previous findings are obtained (as done in many works dealing with the Cournot-Bertrand profit differential) by comparing the profits and welfare results under exogenously given alternative competition regimes, we could also investigate the endogenous competition regime that would arise if application firms are free to choose independently the mode of competition. Second, while this paper considers a "one-sided" pricing strategy where the platform firm sets only an end-user price, also a "two-sided" pricing strategy in which such a firm also sets a per unit access fee (or subsidy) for the applications providers could be considered. Moreover, also the presence of competition between platform firms (which can be either proprietary or open-source) could be investigated.

\section{Appendix}

We provide here (i) the derivation of the demands used by firms $A, 1$, and 2 expressed as a function of the strategic variables, (ii) the explicit expressions for the profits and social welfare differentials mentioned in the main text, and (iii) the formal proofs of the sign of such differentials, with regard to Results 1 and 2 enunciated in the main text.

\section{A. The Case of "Bertrand-Cournot" Competition and the Derivation of the Demands as a Function of the Strategic Variables}

It is useful for the reader to have a more detailed explanation of the achievement of the Nash equilibrium in the case where the application providers choose the Cournot mode of competition, while the platform firm still considers price as choice variable for maximising its profits. 
The demands used by firms $A, 1$, and 2 expressed as a function of the strategic variables $p_{A}, q_{1}$, and $q_{2}$, respectively, are given by the following direct demand function for the platform firm and inverse demand functions for the application firms:

$$
\begin{aligned}
& q_{A}{ }^{C}\left(p_{A}, q_{1}, q_{2}\right) \\
& =\frac{d q_{2}+a_{A}(1-c)-2 a d+\left(1+c-d^{2}\right) p_{A}-d q_{1}}{1-c}, \\
& p_{1}{ }^{C}\left(p_{A}, q_{1}, q_{2}\right) \\
& =\frac{-c q_{2}-q_{1}+a(1-c)-(1+c) d p_{A}}{1-c^{2}}, \\
& p_{2}{ }^{C}\left(p_{A}, q_{1}, q_{2}\right) \\
& =\frac{-c q_{1}-q_{2}+a(1-c)-(1+c) d p_{A}}{1-c^{2}} .
\end{aligned}
$$

By inserting (A.1)-(A.3) in the profit functions (5), (6), and (7), respectively, and performing the usual profit maximisation, the following system of reaction functions in prices and quantities is obtained:

$$
\begin{aligned}
& p_{A}^{C}\left(q_{1}, q_{2}\right)=\frac{d q_{2}+a_{A}(1-c)-d\left(2 a-q_{1}\right)}{2\left(1-c-2 d^{2}\right)}, \\
& q_{1}^{C}\left(p_{A}, q_{2}\right)=\frac{-c q_{1}+a_{A}(1-c)-d(1+c) p_{A}}{2}, \\
& q_{2}^{C}\left(p_{A}, q_{1}\right)=\frac{-c q_{2}+a_{A}(1-c)-d(1+c) p_{A}}{2} .
\end{aligned}
$$

The solution of systems (A.4)-(A.6) gives the equilibrium outcomes in the mixed case in which the platform firm plays
Bertrand and the application firms play Cournot, that is, (14)(19) in main text.

\section{B. Profits and Social Welfare Differentials}

By using (12) and (18), we get

$$
\begin{aligned}
\Delta \pi_{A} & =\frac{1}{2}\left(d \left(a_{A}{ }^{2} c^{4} d^{5}+2 a_{A}{ }^{2} c^{5} d^{3}+2 a_{A}{ }^{2} c^{3} d^{5}\right.\right. \\
& -2 a_{A} a c^{4} d^{4}+4 a_{A} a c^{2} d^{6}-2 a^{2} c^{3} d^{5}+a_{A}{ }^{2} c^{6} d \\
& -3 a^{2} c^{2} d^{5}-4 a_{A} a c^{5} d^{2}+4 a_{A} a c^{3} d^{4}+4 a_{A} a c d^{6} \\
& -4 a^{2} c^{4} d^{3}-10 b^{2} c^{2} d^{5}+4 b^{2} d^{7}-2 a_{A}{ }^{2} c^{5} d \\
& -10 a_{A}{ }^{2} c^{3} d^{3}-4 a_{A}{ }^{2} c d^{5}-2 a_{A} a c^{6}+4 a_{A} a c^{4} d^{2} \\
& +6 a_{A} a c^{2} d^{4}-8 a_{A} a d^{6}-2 a^{2} c^{5} d-12 a^{2} c^{3} d^{3} \\
& +4 a^{2} c d^{5}-3 a_{A}{ }^{2} c^{4} d+4 a_{A}{ }^{2} c^{2} d^{3}+4 a_{A}{ }^{2} d^{5} \\
& +4 a_{A} a c^{5}+16 a_{A} a c^{3} d^{2}-8 a_{A} a c d^{4}-2 a^{2} c^{4} d \\
& +20 a^{2} c^{2} d^{3}+8 a_{A}{ }^{2} c^{3} d+4 a_{A}{ }^{2} c d^{3}+6 a_{A} a c^{4} \\
& -16 a_{A} a c^{2} d^{2}+12 a^{2} c^{3} d-4 a_{A}{ }^{2} c^{2} d-16 a_{A} a c^{3} \\
& \left.\left.-8 a^{2} c^{2} d+8 a_{A} a c^{2}\right)\right)\left(( d ^ { 2 } + c - 2 ) ^ { 2 } \left(c d^{2}+c^{2}\right.\right. \\
+ & \left.\left.3 d^{2}+c-2\right)^{2}(1-c)\right)^{-1} \cdot
\end{aligned}
$$

Result 1 is based on the sign of the above platform's profits differential (B.1) which depends on the model's parameters according to the following threshold value of $a_{A}(a, c, d)$ :

$$
\begin{aligned}
\Delta \pi_{A} & \geq 0 \Longleftrightarrow \\
a_{A} & <a_{A^{\circ}}=\left(a \left[\sqrt{c^{4}(c-1)\left(2 d^{2}+c-1\right)\left(d^{2}+c-2\right)^{2}\left(c d^{2}+c^{2}+3 d^{2}+c-2\right)^{2}}-c^{4} d^{4}+2 c^{2} d^{6}-2 c^{5} d^{2}+2 c^{3} d^{4}\right.\right. \\
& \left.\left.+2 c d^{6}-c^{6}+2 c^{4} d^{2}+3 c^{2} d^{4}-4 d^{6}+2 c^{5}+8 c^{3} d^{2}-4 c d^{4}+3 c^{4}-8 c^{2} d^{2}-8 c^{3}+4 c^{2}\right]\right)\left[d ( 1 - c ) \left(c^{3} d^{4}+2 c^{4} d^{2}\right.\right. \\
& \left.\left.+3 c^{2} d^{4}+c^{5}+2 c^{3} d^{2}-c^{4}-8 c^{2} d^{2}-4 d^{4}-4 c^{3}-4 c d^{2}+4 c^{2}\right)\right]^{-1}
\end{aligned}
$$

By taking profits in (13) and (19) into account, we get

$$
\begin{aligned}
\Delta \pi & =0.5\left[\left(2 a^{2}(1+c)\right) d^{8}+\left(2 a_{A} a\left(1-c^{2}\right)\right) d^{7}\right. \\
& +\left(a_{A}{ }^{2}\left(c^{3}-4\right)-12 a^{2}+c^{2}\left(2 a_{A}{ }^{2}+8 a^{2}\right)\right. \\
& \left.+c\left(a_{A}{ }^{2}-4 a^{2}\right)\right) d^{6}+\left(8 a_{A} a\left(1-c^{3}\right)\right) d^{5} \\
& +\left(14 a c^{3}-c^{2}\left(2 a_{A}{ }^{2}-14 a^{2}\right)-4 c\left(a_{A}{ }^{2}-a^{2}\right)\right.
\end{aligned}
$$

$$
\begin{aligned}
& \left.+8 a^{2}+a_{A}{ }^{2}\left(2 c^{4}+4\right)\right) d^{4}+a_{A} a\left(8 c^{3}-10 c^{4}\right. \\
& \left.+2 c^{2}+8 c-8\right) d^{3}+\left(a_{A}{ }^{2} c^{5}+\left(a_{A}{ }^{2}-16 a^{2}\right) c^{3}\right. \\
& \left.+4 a^{2} c^{2}+\left(12 a^{2}-2 a_{A}{ }^{2}\right) c^{4}\right) d^{2}+a a_{A}\left(8 c^{4}\right. \\
& \left.\left.-4 c^{5}-4 c^{3}\right) d+4 a_{2}{ }^{2}\left(c^{5}-8 c^{4}+4 c^{3}\right)\right]((c-1) \\
& \left.\cdot\left(2-c-d^{2}\right)^{2}\left[(3+c) d^{2}+c^{2}+c-2\right]^{2}\right)^{-1} .
\end{aligned}
$$


Part (i) of Result 2 is based on the sign of the above providers' profits differential (B.3) which depends on the model's parameters according to the following threshold value of $a_{A}(a, c, d)$ :

$$
\begin{aligned}
\Delta \pi_{A} & \geq 0 \Longleftrightarrow \\
a_{A} & \leq a_{A}{ }^{\circ}=\left(a \left[\left(d^{4}(1-c)(1+c)\left(d^{2}+c-2\right)^{2}\right.\right.\right. \\
& \left.\cdot\left(c d^{2}+c^{2}+3 d^{2}+c-2\right)^{2}\right)^{1 / 2}-c^{2} d^{6}-4 c^{3} d^{4} \\
& -5 c^{4} d^{2}+d^{6}-2 c^{5}+4 c^{3} d^{2}+4 c^{4}+c^{2} d^{2}+4 d^{4} \\
& \left.\left.-2 c^{3}+4 c d^{2}-4 d^{2}\right]\right)\left[d ( 1 - c ) \left(c^{2} d^{4}+2 c^{3} d^{2}\right.\right. \\
& \left.\left.+3 c d^{4}+c^{4}+2 c^{2} d^{2}+4 d^{4}-c^{3}-4 d^{2}\right)\right]^{-1} .
\end{aligned}
$$

The expressions for social welfare, by using (20) and (21), in Bertrand and Cournot cases are, respectively,

$$
\begin{aligned}
\mathrm{SW} & =\left(3 a_{A}{ }^{2} c^{2}+\left(2 a_{A}{ }^{2} d^{2}+12 a_{A} a d-12 a_{A}{ }^{2}-8 a^{2}\right)\right. \\
& c+8 a_{A} a d^{3}-2 a_{A}{ }^{2} d^{2}-4 a^{2} d^{2}-32 a_{A} a d \\
& \left.+12 a_{A}{ }^{2}+24 a^{2}\right)\left(8\left(d^{2}+c-2\right)^{2}\right)^{-1} \\
\mathrm{SW}^{C} & =\left[\left(-4 a_{A} a d+3 a^{2}+8 a^{2}\right) c^{5}+\left(-4 a_{A} a d^{3}\right.\right. \\
& \left.+8 a_{A}{ }^{2} d^{2}+16 a^{2} d^{2}+3 a_{A}{ }^{2}\right) c^{4}+\left(4 a_{A}{ }^{2} 2 d^{4}\right. \\
& +8 a^{2} 2 d^{4}-8 a_{A} a d^{3} 3+16 a_{A}{ }^{2} d^{2} 2+24 a^{2} 2 d^{2} \\
& \left.+32 a_{A} a d-15 a_{A}{ }^{2}-40 a^{2}\right) c^{3}+\left(16 a_{A}{ }^{2} d^{4}\right. \\
& +24 a^{2} d^{4}+44 a_{A} a d^{3}-22 a_{A}{ }^{2} d^{2}-72 a^{2} d^{2} \\
& \left.-16 a_{A} a d-3 a_{A}{ }^{2}+24 a^{2}\right) c^{2}+\left(8 a_{A} a d^{5}+4 a_{A}^{2} d^{4}\right. \\
& -16 a^{2} d^{4}+32 a_{A} a d^{3}-36 a_{A}{ }^{2} d^{2}-20 a^{2} d^{2} \\
& \left.-44 a_{A} a d+24 a_{A}{ }^{2}+32 a^{2}\right) c+24 a_{A} a d^{5} \\
& -24 a_{A}{ }^{2} d^{4}-24 a^{2} d^{4}-64 a_{A} a d^{3}+34 a_{A}{ }^{2} d^{2} \\
+ & \left.52 a^{2} d^{2}+32 a_{A} a d-12 a_{A}{ }^{2}-24 a^{2}\right]\left(8 ( c - 1 ) \left(c^{2}\right.\right. \\
+ & \left.\left.\left(d^{2}+1\right)+3 d^{2}-2\right)^{2}\right)^{-1} \cdot
\end{aligned}
$$

By using (B.5), the expression of the social welfare differential is the following:

$$
\begin{gathered}
\Delta \mathrm{SW}=-\left[\left(4 a^{2}-2 a_{A} a d\right) c^{7}+\left(2 a_{A} a d+16 a^{2} d^{2}\right.\right. \\
\left.+3 a_{A}^{2} d^{2}-6 a_{A} a d^{3}-12 a^{2}\right) c^{6}+\left(8 a_{A}{ }^{2} d^{4}\right.
\end{gathered}
$$

$$
\begin{aligned}
& +24 a^{2} d^{4}+18 a_{A} a d-6 a_{A} a d^{5}-4 a_{A} a d^{3} \\
& \left.-8 a_{A}{ }^{2} d^{2}-26 a^{2} d^{2}-12 a^{2}\right) c^{5}+\left(7 a_{A}{ }^{2} d^{6}\right. \\
& +16 a^{2} d^{6}+54 a_{A} a d^{3}+60 a^{2}-2 a_{A} a d^{7}-14 a_{A} a d^{5} \\
& \left.-4 a_{A}{ }^{2} d^{4}-4 a^{2} d^{4}-9 a_{A}{ }^{2} d^{2}-90 a^{2} d^{2}-26 a_{A} a d\right) \\
& \cdot c^{4}+\left(2 a_{A}{ }^{2} d^{8}+4 a^{2} d^{8}+12 a_{A}{ }^{2} d^{6}+22 a^{2} d^{6}\right. \\
& +42 a_{A} a d^{5}+30 a_{A}^{2} d^{2}+180 a^{2} d^{2}-8 a_{A} a d^{7} \\
& \left.-52 a_{A}{ }^{2} d^{4}-160 a^{2} d^{4}-16 a_{A} a d^{3}-56 a^{2}\right) c^{3} \\
& +\left(8 a_{A}^{2} d^{8}+12 a^{2} d^{8}+10 a_{A} a d^{7}+18 a_{A} a d^{5}\right. \\
& +28 a_{A}{ }^{2} d^{4}+144 a^{2} d^{4}+8 a_{A} a d+16 a^{2}-37 a_{A}{ }^{2} d^{6} \\
& \left.-90 a^{2} d^{6}-28 a_{A} a d^{3}-80 a^{2} d^{3}\right) c^{2}+\left(4 a_{A} a d^{9}\right. \\
& +2 a_{A}{ }^{2} d^{8}+12 a_{A} a d^{7}+4 a^{2} d^{6}+76 a_{A}{ }^{2} d^{4} \\
& +24 a^{2} d^{4}-8 a^{2} d^{8}-38 a_{A}{ }^{2} d^{6}-24 a_{A} a d^{5} \\
& \left.-16 a_{A} a d^{3}-32 a_{A}{ }^{2} d^{2}\right) c+12 a_{A} a d^{9}-12 a_{A}{ }^{2} d^{8} \\
& -44 a_{A} a d^{7}+56 a_{A}{ }^{2} d^{6}-56 a^{2} d^{6}-32 a^{2} d^{4} \\
& \left.+16 a_{A} a d^{3}+16 a^{2} d^{2}\right]\left(4 \left\{(c-1)\left(2-c-d^{2}\right)\right.\right. \\
& \left.\left.\cdot\left[c^{2}+c\left(d^{2}+1\right)+3 d^{2}-2\right]^{2}\right\}\right)^{-1} \text {. }
\end{aligned}
$$

Part (ii) of Result 2 is based on the sign of the above social welfare differential (B.6) which depends on the model's parameters according to the following threshold value of $a_{A}(a, c$, d):

$$
\begin{aligned}
\Delta \mathrm{SW} & \underset{<}{>} 0 \\
a_{A} & \geq a_{A}{ }^{\circ 00}=a\left[\left(\left(c^{6} d^{4}-8 c^{4} d^{6}+2 c^{7} d^{2}-26 c^{5} d^{4}\right.\right.\right. \\
& -12 c^{3} d^{6}+c^{8}-30 c^{6} d^{2}+13 c^{4} d^{4}+28 c^{2} d^{6}+4 d^{8} \\
& -12 c^{7}+60 c^{5} d^{2}+120 c^{3} d^{4}+8 c d^{6}+34 c^{6} \\
& +52 c^{4} d^{2}-116 c^{2} d^{4}-24 d^{6}-12 c^{5}-160 c^{3} d^{2} \\
& \left.-24 c d^{4}-51 c^{4}+76 c^{2} d^{2}+36 d^{4}+56 c^{3}-16 c^{2}\right) \\
& \left.+\left(d^{2}+c-2\right)^{2}\left(c d^{2}+c^{2}+3 d^{2}+c-2\right)^{2}\right)^{1 / 2} \\
& -2(c+3) d^{8}+\left(c^{4}+4 c^{3}-5 c^{2}-6 c+22\right) d^{6} \\
& +\left(3 c^{5}+7 c^{4}-21 c^{3}-9 c^{2}+12 c\right) d^{4}+\left(3 c^{6}+2 c^{5}\right. \\
& \left.-27 c^{4}+8 c^{3}+14 c^{2}+8 c-8\right) d^{2}+c^{7}-c^{6}
\end{aligned}
$$




$$
\begin{aligned}
& \left.-9 c^{5}+13 c^{4}-4 c^{2}\right]\left(\left\{( c - 1 ) \left[\left(2 c^{2}+10 c+12\right) d^{6}\right.\right.\right. \\
& +\left(7 c^{3}+19 c^{2}-18 c-56\right) d^{4} \\
& +\left(8 c^{4}+4 c^{3}-48 c^{2}-20 c^{4}+56\right) d^{2} \\
& \left.\left.\left.+\left(3 c^{5}-5 c^{4}-14 c^{3}+16 c^{2}+16 c-16\right) d\right]\right\}\right)^{-1}
\end{aligned}
$$

\section{Competing Interests}

The authors declare that there is no conflict of interests regarding the publication of this article.

\section{Endnotes}

1. Their model is based on Dixit's [23] differentiated duopoly model with linear demand structure and exogenous (constant) marginal costs.

2. As shown by Economides and Katsamakas (2006), there is equivalence between a specification of the demand functions which assumes complementarities and a specification which assumes explicit network effects across the two sides of the market (users and application providers).

3. Note that the previous literature has tackled the issue of the comparison of the two modes of competition in a standard "one-sided" market. To the best of our knowledge, this paper is a first attempt to consider such an issue in a "two-sided" market.

4. Note that this is a single-sided price strategy because it considers only one side, the end-users, of the two-sided market. Another pricing strategy considers both sides of the market, a "two-sided" pricing strategy, which, in addition to selling to end-users, sets a per unit access fee (or subsidy) to applications providers. However, to apply such fees, the platform firm should be able to anticipate and monitor the sales of application providers, which can result to be difficult especially when providers are numerous and, in any case, expensive. In the words of Economides and Katsamakas $(2006,1063)$, "a two-sided pricing strategy can be costly to implement (for example, to implement the two-sided strategy the platform firm needs to keep track of the sales of the application providers)." Although preliminary results indicate that our paper's results qualitatively hold also in this case, it is left for future research.

5. As in Economides and Katsamakas (2006), the same parameter $d$ measures the strength of the complementarity between the platform and each application. However, each application could have its own demand parameter, namely, $d_{1}$ and $d_{2}$, as suggested by a referee. The introduction of this more general demand system deserves to be investigated in future research.

6. The reason why platform sales may be larger than applications sales is that platform users might not need to buy some applications: by using the example of Economides and Katsamakas $(2006,1060)$ "Windows contains a browser, an e-mail application, a media player, and word processing features, and some users may find these features sufficient and not buy any applications."

7. In this paper, for the sake of simplicity, we allow for the choice of alternative modes of competition only for application providers. However, in principle, it is possible for application providers to compete in price (resp., output) and it is possible for the network provider to compete in output (resp., price). Moreover, also application firm 1 could behave as a Cournot-type (resp., Bertrand-type) firm and application firm 2 could behave as a Bertrand-type (resp., Cournot-type) firm. The investigation of this richer taxonomy of competitive behaviours in the software industry is left for future research. We thank an anonymous referee for having pointed out this possibility.

8. For simplicity, hereafter, we use Bertrand (resp., Cournot) to denote the "Bertrand-Bertrand" (resp. "Bertrand-Cournot") case.

9. The social welfare in this market model is the sum of the surpluses of all the agents participating in the market, that is, consumers and producers.

10. The behaviours of consumer surplus and social welfare are qualitatively the same and thus it is sufficient to present results for social welfare (which holds true for consumer surplus as well).

11. However, as a referee has pointed out, there are social gains as well as costs to product differentiation, and given that the current model is based on specific assumptions (and therefore is not too general) this cannot suggest in a clear-cut way that there would be too much differentiation among application providers.

12. These findings have been based, as the benchmark model of Singh and Vives (1984), on a linear demand system. Their robustness to more general demand functions should be investigated in future research.

\section{References}

[1] N. Singh and X. Vives, "Price and quantity competition in a differentiated duopoly," RAND Journal of Economics, vol. 15, no. 4, pp. 546-554, 1984.

[2] J.-C. Rochet and J. Tirole, "Platform competition in two-sided markets," Journal of the European Economic Association, vol. 1, no. 4, pp. 990-1029, 2003.

[3] E. Katsamakas and Y. Bakos, "Design and ownership of twosided networks," Journal of Economic Perspectives, vol. 19, no. 2, pp. 99-120, 2005.

[4] M. Armstrong, "Competition in two-sided markets," RAND Journal of Economics, vol. 37, no. 3, pp. 668-691, 2006.

[5] M. Rysman, "The economics of two-sided markets," Journal of Economic Perspectives, vol. 23, no. 3, pp. 125-143, 2009.

[6] L. Cheng, "Comparing bertrand and cournot equilibria: a geometric approach," The RAND Journal of Economics, vol. 16, no. 1, pp. 146-152, 1985. 
[7] X. Vives, "On the efficiency of Bertrand and Cournot equilibria with product differentiation," Journal of Economic Theory, vol. 36, no. 1, pp. 166-175, 1985.

[8] K. Okuguchi, "Equilibrium prices in the Bertrand and Cournot oligopolies," Journal of Economic Theory, vol. 42, no. 1, pp. 128139, 1987.

[9] P. Zanchettin, "Differentiated duopoly with asymmetric costs," Journal of Economics \& Management Strategy, vol. 15, no. 4, pp. 999-1015, 2006.

[10] A. Chirco and M. Scrimitore, "Choosing price or quantity? The role of delegation and network externalities," Economics Letters, vol. 121, no. 3, pp. 482-486, 2013.

[11] R. Pal, "Cournot vs. Bertrand under relative performance delegation: implications of positive and negative network externalities," Mathematical Social Sciences, vol. 75, pp. 94-101, 2015.

[12] M. Alipranti, C. Milliou, and E. Petrakis, "Price vs. quantity competition in a vertically related market," Economics Letters, vol. 124, no. 1, pp. 122-126, 2014.

[13] A. Mukherjee, U. Broll, and S. Mukherjee, "Bertrand versus cournot competition in a vertical structure: a note," Manchester School, vol. 80, no. 5, pp. 545-559, 2012.

[14] X. Nguyen, P. Sgro, and M. Nabin, "Licensing under vertical product differentiation: price vs. quantity competition," Economic Modelling, vol. 36, pp. 600-606, 2014.

[15] L. Fanti and N. Meccheri, "The Cournot-Bertrand profit differential in a differentiated duopoly with unions and labour decreasing returns," Economics Bulletin, vol. 31, no. 1, pp. 233244, 2011.

[16] K. Choi, "Price and quantity competition in a unionised mixed duopoly: the cases of substitutes and complements," Australian Economic Papers, vol. 51, no. 1, pp. 1-22, 2012.

[17] L. Fanti and N. Meccheri, "On the Cournot-Bertrand profit differential and the structure of unionisation in a managerial duopoly," Australian Economic Papers, vol. 54, no. 4, pp. 266287, 2015.

[18] J. Hinloopen and J. Vandekerckhove, "Dynamic efficiency of cournot and bertrand competition: input versus output spillovers," Journal of Economics, vol. 98, no. 2, pp. 119-136, 2009.

[19] J. Hinloopen and J. Vandekerckhove, "Product market competition and investments in cooperative R\&D," The B.E. Journal of Economic Analysis and Policy, vol. 11, no. 1, article no. 55, 2011.

[20] C. H. Tremblay and V. J. Tremblay, "The Cournot-Bertrand model and the degree of product differentiation," Economics Letters, vol. 111, no. 3, pp. 233-235, 2011.

[21] V. J. Tremblay, C. H. Tremblay, and K. Isariyawongse, "Endogenous timing and strategic choice: the Cournot-Bertrand model," Bulletin of Economic Research, vol. 65, no. 4, pp. 332-342, 2013.

[22] N. Economides and E. Katsamakas, "Two-sided competition of proprietary vs. open source technology platforms and the implications for the software industry," Management Science, vol. 52, no. 7, pp. 1057-1071, 2006.

[23] A. K. Dixit, "A model of duopoly suggesting a theory of entry barriers," Bell Journal of Economics, vol. 10, no. 1, pp. 20-32, 1979. 


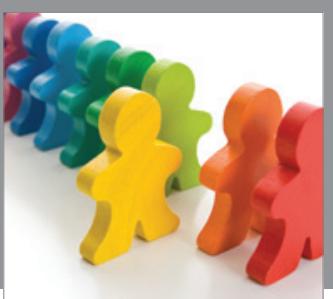

Autism

Research and Treatment
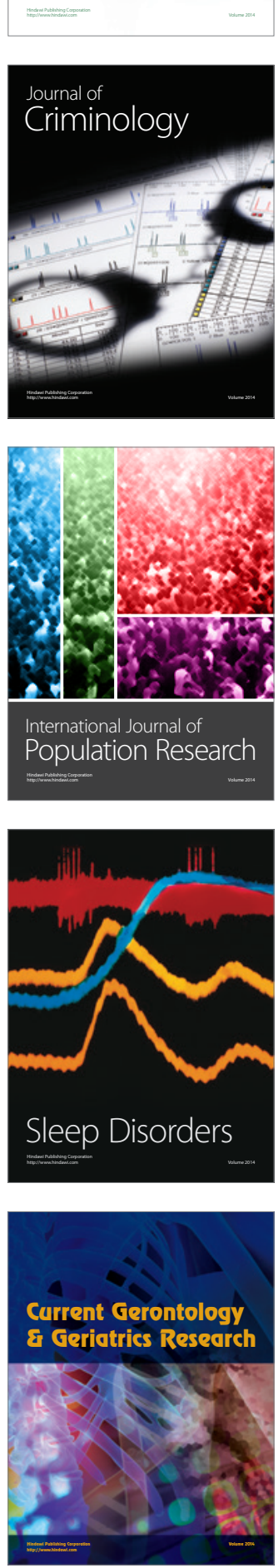

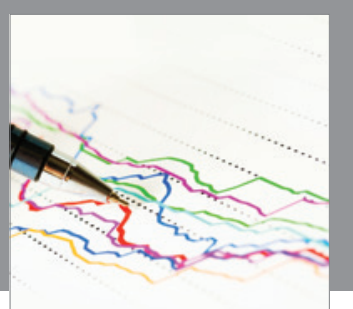

Economics

Research International
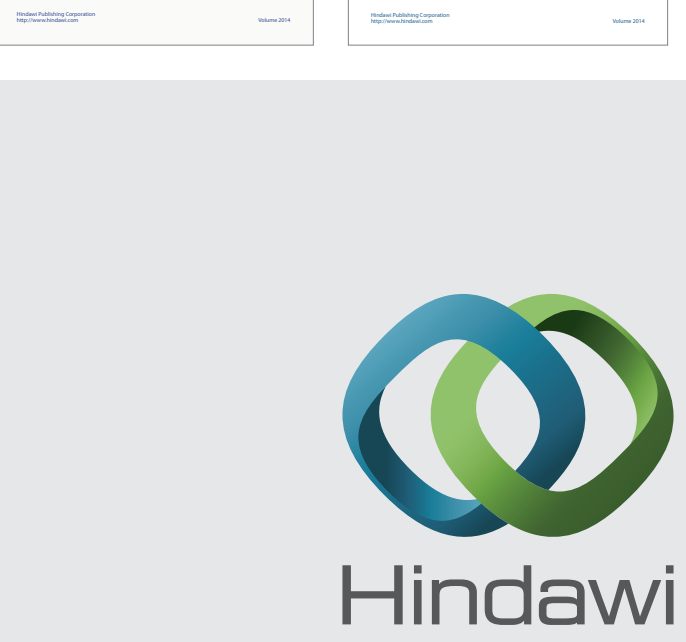

Submit your manuscripts at

https://www.hindawi.com
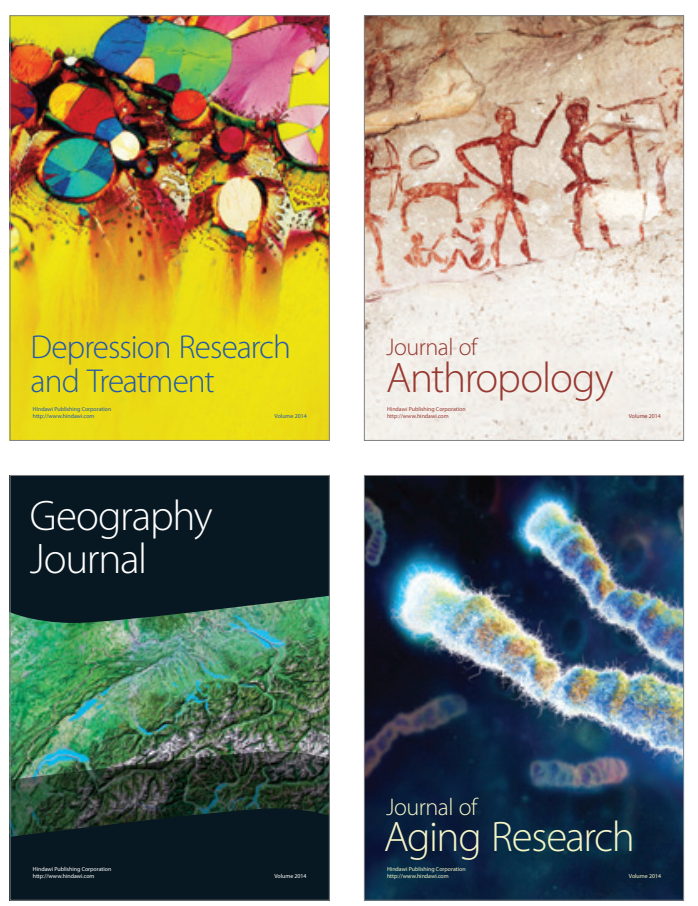
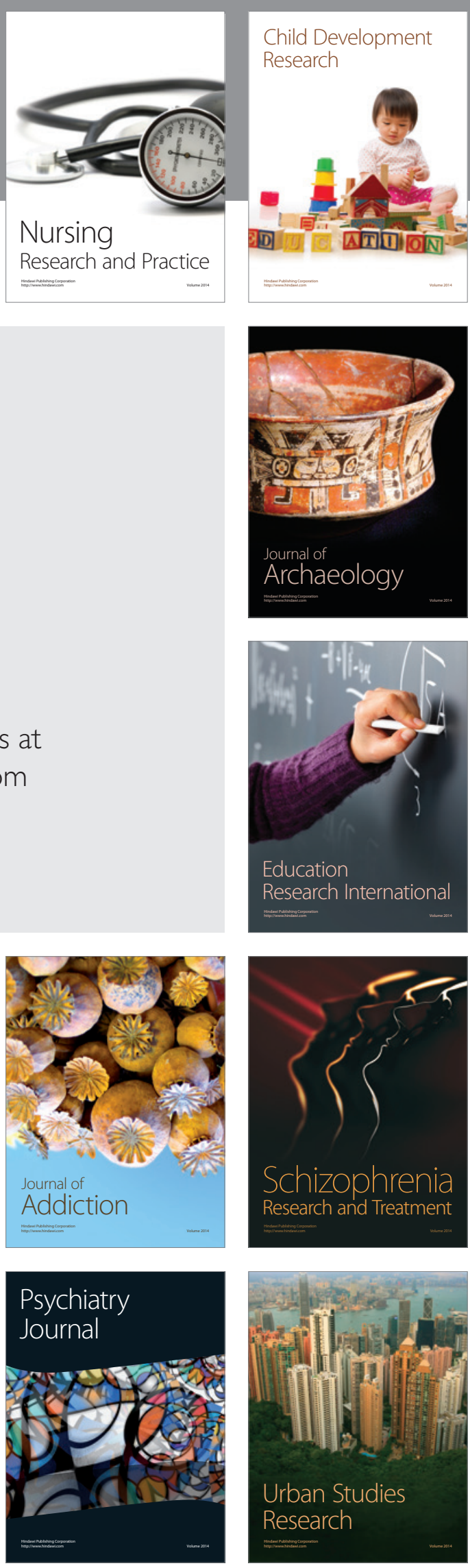